Universidad de Lima

Facultad de Comunicación

Carrera de Comunicación

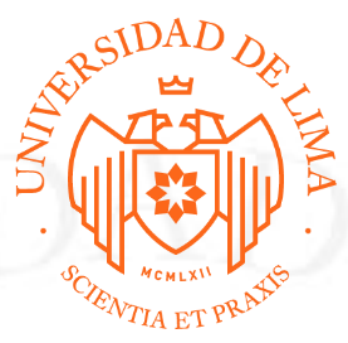

\title{
"LA GESTIÓN DE LA COMUNICACIÓN EN SITUACIONES DE CRISIS: EL CASO CONGA"
}

Tesis para optar el Título Profesional de Licenciado en Comunicación

Esther Elena Lozano Rojas

Código 20092395

\section{Asesor}

Rosario Sheen Merino

Lima - Perú

Marzo de 2020 


\section{LA GESTIÓN DE LA COMUNICACIÓN EN SITUACIONES DE CRISIS: \\ EL CASO CONGA}




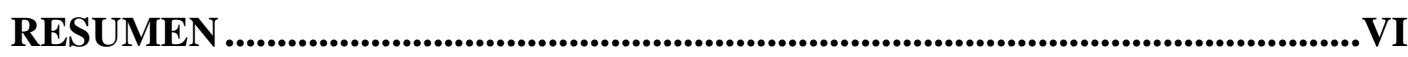

ABSTRACT .....................................................................................................

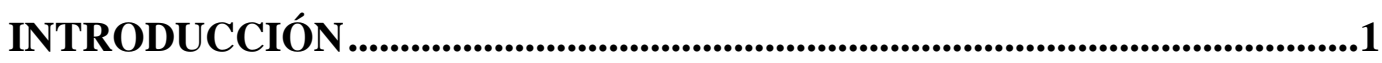

CAPITULO I: EL PROYECTO MINERO .....................................................2

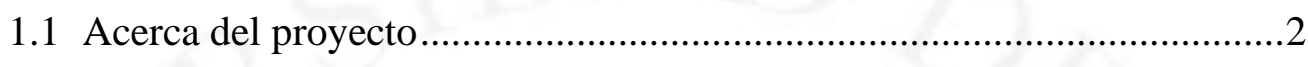

1.2 La economía de Cajamarca .................................................................

CAPITULO II: LA CRISIS CONGA..................................................................4

2.1. Antecedentes de la crisis ..................................................................

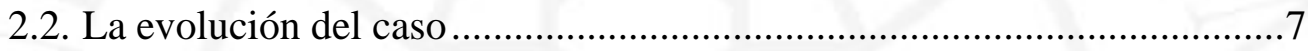

2.3. Evolución de la crisis: resumen gráfico ................................................. 18

2.4. Actores centrales de la crisis: ............................................................ 19

CAPITULO III: ANÁLISIS DE LA CRISIS...................................................22

CAPITULO IV: MARCO CONCEPTUAL ............................. 29

4.1. Las organizaciones en la era de la transparencia: Rol de los stakeholders ....29

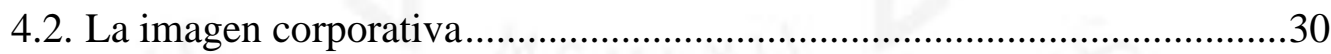

4.3. La gestión de crisis en el siglo XXI ............................. 31

V. CONCLUSIONES .....................................................................................34

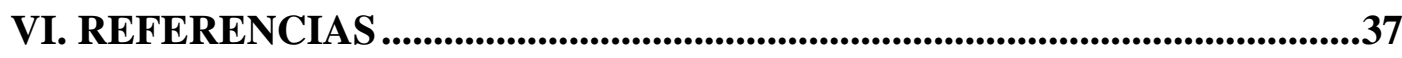




\section{ÍNDICE DE FIGURAS}

Figura 1: Evolución de la crisis Conga .................................. 18 


\section{RESUMEN}

El presente trabajo académico se enfoca en la crisis de la empresa minera Yanacocha que se desencadenó a raíz de la oposición de la población de Cajamarca al proyecto de explotación aurífera Conga en ese departamento, y cuya etapa más sensible fue entre octubre 2011 y octubre 2012 ,

Se trata del análisis del caso desde el punto de vista de la comunicación de crisis y a partir de los hechos descritos por los medios masivos sobre la respuesta de la empresa a tal crisis, y cómo los acontecimientos impactaron en la imagen corporativa de la empresa propietaria del proyecto.

Con base a la información que reportaron entonces los medios de comunicación locales y nacionales, examinamos cómo discurrió el conflicto social Conga, el cual se convirtió en suceso también político, hasta derivar en una crisis de altas proporciones que terminó en 2012 con el cierre del proyecto.

Al revisar las reacciones de Yanacocha en el referido período, y la posición que reafirmó luego la empresa para este trabajo (por vía de uno de sus representantes), veremos la forma inefectiva en que la compañía manejó uno de los componentes claves de la gestión de crisis: la comunicación.

Palabras clave: Gestión de crisis, comunicación de crisis, imagen corporativa 


\begin{abstract}
This academic work is an analysis of the corporate crisis of the mining company Yanacocha, whose key gold mining project, Conga, located in the Peruvian department of Cajamarca, was rejected by the local population since the beginning in 2010 , and finally cancelled in October 2012.

It is a communication analysis based on the news coverage of the events between October 2011 and October 2012, the most sensible period for the project. The coverage showed the company's inappropriate responses to the crisis and how they damaged its corporate image.

Using information from the local and national mass media, we review how the social conflict evolved, how it became also a political news story, until it bursted into a high-impact crisis that led to the closure of the Conga project.

We examine Yanacocha's handling of the crisis and observe the ineffective approach around a critical component in crisis management: crisis communication.
\end{abstract}

Key words: Crisis management, crisis communication, corporate image. 


\section{INTRODUCCIÓN}

La crisis corporativa más grande que atravesó la empresa minera Yanacocha en Perú fue la del proyecto Conga, el cual iba a llevar inmensos beneficios económicos al departamento de Cajamarca, uno de los más pobres del país, según planeaba la empresa. La compañía jamás imaginó la firme oposición que encontraría en la población de ese departamento.

Para este trabajo hemos examinado los hechos durante el año más fuerte de la crisis y observado, mediante la cobertura noticiosa de ese período, cómo respondió la empresa a esta situación y cómo sus respuestas repercutieron en su imagen corporativa. Asimismo, hemos conocido, por fuente directa, qué piensa hoy en día Yanacocha a respecto a los hechos de entonces y sus argumentos para responder a los acontecimientos del modo en que lo hizo.

Los sucesos analizados abarcaron el período octubre de 2011 a octubre de 2012. Los medios de prensa que usamos para el análisis fueron el diario local Panorama Cajamarquino el de mayor lectoría en Cajamarca, los diarios nacionales El Comercio y La República; la televisora América TV, Latina TV, Canal N y TV-Norte Cajamarca, y la radioemisora RPP. En la empresa minera, entrevistamos al gerente de comunicaciones.

El trabajo busca mostrar cómo las crisis en las organizaciones se desbordan no tanto por los hechos mismos que las desencadenan como por el mal manejo que las empresas que están en el centro del problema hacen de la crisis. Al mismo tiempo, intenta aportar a la discusión acerca de cómo aprovechar un elemento insustituible en la gestión de crisis, cual es la comunicación (desde la mirada de la empresa), y presentar las respuestas esenciales o mínimas que deben desplegar las organizaciones a fin de reducir los impactos negativos en su imagen. 


\section{CAPITULO I: EL PROYECTO MINERO}

\subsection{Acerca del proyecto}

En 2004 Conga era el proyecto estrella de explotación de oro y plata de Yanacocha, la empresa más grande de Sudamérica y la segunda más grande a nivel mundial en el sector aurífero (Zazo, 2017). Yanacocha tiene como accionistas a Newmont Mining Corporation, EEUU, (54\% de acciones); a Minas Buenaventura, Perú (45.95\%); y a la Corporación Financiera Internacional (5\%), miembro del Grupo del Banco Mundial (Minera Yanacocha S.R.L., 2011, p. 18).

La mina está localizada a $73 \mathrm{~km}$ de la ciudad capital de Cajamarca, en los distritos de Sorochuco y Huasmín (provincia de Celendín) y de La Encañada (provincia de Cajamarca). En noviembre 2010 el gobierno peruano aprobó el convenio de operación de la mina por dos décadas hasta el año 2030.

En 2012, Conga llegó a emplear 3,739 trabajadores, y contaba con unas 38 empresas proveedoras: 16 eran locales y el resto, principalmente, de Lima.

En octubre de 2011, es decir a menos de un año del inicio de las operaciones, el proyecto ocupó las primeras planas de los medios nacionales e internacionales al ser el escenario del inicio de un intenso conflicto entre la empresa y las comunidades aledañas. El motivo fue el rechazo de la población a la explotación de la mina que, según los habitantes, afectaba el medio ambiente y, particularmente, a cuatro lagunas consideradas como la fuente principal de agua de unos 200 caseríos de la región. La explotación, señalaban los pobladores, ocasionaría la contaminación y la escasez de agua.

Los reclamos y protestas por la inviabilidad de proyecto se agudizaron y desencadenaron una serie de acciones que paralizaron las actividades comerciales, el turismo y el trasporte en la ciudad de Cajamarca. El rechazo fue creciendo a tal punto que, pocas semanas después, prácticamente todo el departamento de Cajamarca se oponía al proyecto minero. La población veía este problema como un enfrentamiento "entre David y goliat". 
El conflicto se convertiría en la disputa más grande en Perú por el recurso del agua, y entre la población y la empresa privada. Convertido en una crisis que seguía creciendo, el enfrentamiento se trajo abajo el proyecto en agosto del 2012, mes en que la empresa anunció el cierre del mismo.

\subsection{La economía de Cajamarca}

Al año 2012, Cajamarca tenía algo más de un millón y medio de habitantes, de los cuales el $32,7 \%$ era población urbana y el $67.3 \%$ rural (Instituto Nacional de Estadística e Informática [INEI], 2014).

Durante el siglo XX, Cajamarca basó su economía en actividades de explotación de recursos naturales siendo la agricultura y ganadería su principal fuente de empleo, abasteciendo sus productos en los mercados locales. Desde 1990 la economía local dio un giro positivo con el ingreso de la minería que hizo crecer el sector de la construcción privada y pública. Sin embargo, este auge solo se vio reflejado en las zonas urbanas de Cajamarca; el área rural fue desatendida por el gobierno y los progresos en desarrollo económico fueron muy lentos, situación que disgustó a la población rural de los numerosos caseríos.

Mientras que entre 2012 y 2018 Perú experimentó un crecimiento económico del 15.23 \% del PIB, el PBI de Cajamarca llegó a sólo 2.7\%. Se registró no solo eso. El índice de pobreza en el departamento aumentó a 54,2\% en el mismo período, y ello convirtió al departamento en la segunda región más pobre del Perú. Solo en 2018 el índice porcentual de pobreza fue de 47,5\%, mayor al promedio estándar de Perú (Banco Central de Reserva del Perú [BCR], 2018; INEI, 2018a, 2018b).

La presencia de Yanacocha en Cajamarca no hizo mucho por mejorar esas cifras de la débil economía cajamarquina, y este era uno de los argumentos de la población cajamarquina para expresar su oposición al proyecto Conga. 


\section{CAPITULO II: LA CRISIS CONGA}

\subsection{Antecedentes de la crisis}

Una serie de crisis previas fueron el insumo para la creciente percepción negativa de la población hacia las actividades mineras y el rechazo al proyecto Conga.

Revisemos brevemente estos conflictos:

\section{Crisis 1: Denuncias por abusos en la compra de terrenos (1993)}

Esta crisis se inició en abril de 1993 cuando la empresa Yanacocha -que se alistaba para iniciar sus operaciones en Cajamarca- compró a los pobladores una cantidad de terrenos en los distritos de las zonas de influencia del proyecto (Cajamarca mismo, Baños del Inca, La Encañada y Chetilla). La compra fue a precios muy bajos del mercado, entre 50 y 100 soles por hectárea de terreno y hasta un máximo de 300 soles. A pesar de estos precios subvaluados, la operación de compra se concretó entre la empresa y los pobladores. Pero a los pocos meses (en agosto), los pobladores comenzaron a oponerse a los trabajos mineros. Según ellos, la entrada de la empresa a yacimiento de exploración se hizo sin contar con la ordenanza municipal respectiva, algo que consideraron como un abuso de poder.

La empresa desestimó el reclamo y prosiguió con sus planes; mientras tanto el malestar social quedó latente.

\section{Crisis 2: Contaminación de la piscigranja Porcón (2000-2001)}

El nuevo siglo comenzó con otro problema para Yanacocha. El año 2000 las poblaciones cercanas a la piscigranja del centro poblado de Porcón, que era fuente de ingresos para muchas familias dedicadas a la crianza de truchas, denunciaron la existencia de metales pesados en el agua como resultado de las operaciones mineras. Ellos manifestaron que tanto la piscigranja como los ríos contiguos San Miguel y Jequetepeque 
que proveen de agua a cuatro provincias de Cajamarca y a la provincia de Pacasmayo (departamento de La Libertad), estaban contaminados.

La contaminación, según los campesinos, había causado ya la muerte de 12,000 truchas. Yanacocha negó su responsabilidad en el problema, pero instaló otra piscigranja en un lugar lejos de los ríos afectados.

El 2001, a raíz de las denuncias, grupos de la sociedad civil de Cajamarca crearon el Frente Departamental de Defensa de Intereses del Pueblo y Medio Ambiente de Cajamarca. Junto con el Municipio Provincial también abrieron una Comisión Multisectorial que se encargaría de atender las denuncias de la población y plantear soluciones a cualquier problema causado por la minería. Una primera acción fue pedir la instalación de un laboratorio para monitorear la calidad del agua en la zona de influencia, pedido que atendió Yanacocha ante la presión social.

\section{Crisis 3: Derrame de mercurio en Choropampa (2000).}

El 2 de junio de 2000 un camión de la empresa peruana RANSA, subcontratada por Yanacocha para trasladar insumos para la minería, derramó en la vía pública del distrito de Choropampa (en el trayecto de Cajamarca hacia Lima), $151 \mathrm{~kg}$ de mercurio metálico que acarreaba en su interior. Los pobladores de Choropampa, desconocedores del peligro de esa sustancia, comenzaron a jugar con las "bolitas" de mercurio. El impacto en su salud fue inevitable: se intoxicaron 755 personas, según un reporte de la Defensoría del Pueblo (Defensoría del Pueblo [DP], 2001).

La empresa salió a responder después de 12 días del incidente, luego de las protestas de la población y la presión de los medios. En un comunicado, admitió que la intoxicación fue consecuencia de la exposición de mercurio en la zona. La gravedad del hecho hizo que el caso sea noticia también internacional con serios cuestionamientos a la conducta de Yanacocha.

"Un informe posterior de la Defensoría del Pueblo señaló que las botellas de mercurio que la empresa enviaba a la mina no tenían los rótulos que indicaran su contenido y el peligro que representaban. También indicó que la compañía no aplicaba las normas internacionales sobre el manejo y transporte de materiales peligrosos" (ibid., p.48-51). 


\section{Crisis 4: Protestas por la explotación en el Cerro Quilish (2004).}

El cerro Quilish, ubicado en la capital de Cajamarca, es considerado la fuente principal de agua para consumo humano y agrícola en Cajamarca. El año 2000 el municipio de Cajamarca lo declaró “Zona Reservada Protegida Municipal”, y esto obligó a la empresa a suspender sus operaciones en el lugar. Sin embargo, poco después, Yanacocha recurrió a las instancias judiciales para volver a operar, a pesar de las protestas de la población.

En abril 2003 logró que el Tribunal Constitucional le autorice explotar la zona del cerro, y en julio de 2004 el Ministerio de Energía y Minas le autorizó reiniciar la exploración y explotación de Quilish. La noticia provocó de inmediato protestas en Cajamarca, la paralización del transporte y enfrentamientos de los pobladores con la policía.

Las protestas se transformaron pronto en la crisis más grande para la empresa hasta ese momento. El 15 de setiembre de 2004, más de 50,000 personas se congregaron en la Plaza de Armas de Cajamarca para exigir la intangibilidad del cerro. Al día siguiente, el Ministerio de Energía y Minas dio marcha atrás y suspendió la autorización de julio. Yanacocha, consecuentemente, canceló definitivamente sus operaciones en el lugar.

\section{Crisis 5: Protestas en Combayo (2006).}

Esta crisis se inició en junio de 2005 cuando la empresa, como parte de su plan de expansión minera, decidió construir un dique ("El Azufre”) en el caserío de Combayo, distrito de La Encañada. Los pobladores expresaron que no habían sido informados sobre la obra y sobre los efectos que tendría en la reserva de agua de la zona, y exigieron suspensión de los trabajos. La empresa logró que la población aceptara la obra a cambio de una inversión en obras de desarrollo local por 15 millones.

El acuerdo no satisfizo a los pobladores, y al año siguiente volvieron las protestas. Esta vez los enfrentamientos con el personal de seguridad de la empresa y la policía dejaron un poblador muerto. Los sucesos fueron noticia también internacional. La presión de los pobladores obligó a la empresa a suspender el proyecto en Combayo y con esto también paralizó la inversión social en la zona. 
Con el antecedente de cinco crisis previas, el proyecto Conga comenzaba en un entorno muy adverso. No era difícil imaginar los acontecimientos aún mayores que estaban por llegar.

\subsection{La evolución del caso}

En atención al requisito exigido por el gobierno, el 9 de febrero de 2010, Yanacocha presentó al Ministerio de Energía y Minas el Estudio de Impacto Ambiental (EIA) del proyecto Conga, el cual recibió la aprobación gubernamental meses después, en octubre del mismo año. La noticia se difundió, pero no convenció a la población local que siguió afirmando que la actividad minera afectaría a cuatro lagunas consideradas como fuentes principales de agua del departamento.

En julio de 2011, la empresa dio inicio al proyecto Conga. Era un año electoral y meses antes Cajamarca había recibido al entonces candidato Ollanta Humala (que se convertiría en presidente del país en julio de 2011), quien durante su campaña electoral prometió cuidar los recursos naturales del departamento. Famosa fue la frase que Humala repitió varias veces en campaña: “Agua sí, oro no” (refiriéndose a la explotación aurífera) y que meses después la población cajamarquina usaría para echar en cara a su gobierno del incumpliendo de sus promesas.

Repasemos los principales hechos:

- $\quad$ En octubre de 2011, la insatisfacción social en Cajamarca ante la actividad minera se hizo nuevamente pública. Comenzaron las protestas de los pobladores, que incluyeron obstaculización de la vía de ingreso a la mina, bloqueo de la carretera Cajamarca-Bambamarca, quema de maquinaria usadas en las operaciones, y un ultimátum a la empresa para que se retire del yacimiento Conga.

\section{Reacciones de Yanacocha:}


1. A través de comunicado de prensa difundido por los medios locales, la empresa censuró las protestas y actos de violencia y dijo que demandaría a los responsables de estos actos. Responsabilizó al alcalde del distrito de La Encañada "por instigar a población a reclamar 20 millones de compensación por los trabajos mineros" (“Comuneros quemaron maquinaria pesada de empresa minera"1, 2011).

2. Los empleados de Yanacocha, encabezados por su gerente general, realizaron una marcha pacífica por las principales calles de la ciudad de Cajamarca portando carteles a favor de las operaciones mineras. Al ser entrevistado, el gerente reconoció por primera vez la necesidad de dialogar con las comunidades y negó que haya existido problemas de contaminación ambiental a causa de las operaciones mineras de la compañía.

3. La empresa publicó en YouTube un video corporativo donde muestra escenas de la marcha de empleados el mismo día. Debajo del video escribió un mensaje con el que desestimaba las protestas sociales y se centraba en alabar la marcha: "Por si alguna duda quedó sobre la cantidad de gente que marchó por la paz el diálogo y el desarrollo", rezaba la leyenda del video (Minera Yanacocha S.R.L., 2011). ${ }^{2}$

4. En entrevista con un diario cajamarquino, el gerente de responsabilidad social del proyecto reiteró que no hay conflicto social alguno y, por el contrario, afirmó que 32 centros poblados del área de influencia del proyecto estaban de acuerdo con éste.

5. Representantes de la compañía asistieron a una reunión (conocida como "mesa de diálogo") con las autoridades locales y representantes de la sociedad civil. En la reunión, que fue convocada por el Ministerio de Energía y Minas, ellos señalaron que el Estudio de Impacto Ambiental presentado en 2010 refleja que las operaciones de Conga cumplen con todos los estándares ambientales.

\footnotetext{
${ }^{1}$ Noticia periodística en diario Panorama Cajamarquino.

${ }^{2}$ Video realizado por Minera Yanacocha.
} 
- En noviembre de 2011, se produjeron las reacciones sociales más fuertes: el Gobierno Regional llamó a la población a un paro indefinido. En la semana del 9 de noviembre en adelante, se paralizaron completamente el comercio local, el transporte urbano y aéreo, las clases escolares y universitarias, y las actividades institucionales. Los pobladores bloquearon varias vías de acceso a la ciudad y, al mismo tiempo, en los distritos contiguos a la mina (Huasmín, Sorochuco, Bambamarca y La Encañada) los residentes irrumpieron por la fuerza en las instalaciones del proyecto.

Se produjeron enfrentamientos con la Policía Nacional que dejaron 19 heridos entre civiles y policías. Ante esta creciente insurrección, la empresa decidió suspender las actividades mineras temporalmente.

\section{Reacciones de Yanacocha:}

1. En entrevista con un canal de televisión de Lima, el gerente general ratificó que el Estudio de Impacto Ambiental de Conga fue aprobado por el Ministerio de Energía y Minas y consideró que no era necesario hacer un estudio adicional.

2. En entrevista con un canal de televisión de Lima, el vicepresidente legal de Newmont Sudamérica insistió en que la empresa no renunciaría a proyecto Conga.

3. Ante un diario local en Cajamarca, el gerente de la empresa Buenaventura (socia de Yanacocha) reiteró la necesidad de dialogar con las comunidades para poner fin a protestas, y de ese modo no enviar un mensaje negativo al país y al extranjero sobre la inversión privada.

4. La empresa a través de su vocero, el gerente general, anunció la suspensión temporal de sus operaciones en Conga. Lo hizo en Palacio de Gobierno junto al Presidente de Concejo de Ministros.

5. Por su lado el vicepresidente legal de Newmont Sudamérica, en entrevista con un canal televisivo de Lima, afirmó que no hay impacto negativo en las fuentes hidrográficas de la zona delimitada del proyecto Conga. 
- Las protestas, sin embargo, continuaron. En diciembre 2011, el Ministerio del Interior declaró el estado de emergencia en cuatro provincias de Cajamarca (Cajamarca, Celendín, Hualgayoc y Contumazá). Días después, el presidente del Consejo de Ministros renunció a su cargo (los medios de prensa expresaron que el mal manejo gubernamental del caso Conga fue uno de los detonantes para su renuncia). El conflicto disminuyó parcialmente unos meses, pero el descontento de la población continuó. El estado de emergencia se mantuvo hasta el 16 de ese mes.

El 26 de diciembre se instaló una mesa de diálogo entre representantes del gobierno peruano, autoridades del gobierno local y sociedad civil. En la reunión se acordó que el Estado financiaría un "dictamen pericial internacional del componente hídrico" del Estudio de Impacto Ambiental del proyecto aprobado el año 2010. Los resultados determinarían sí la explotación minera ocasiona daños ambientales en los recursos hídricos de la zona.

Dos días después de la "mesa de diálogo", el Presidente Regional de Cajamarca declaró de interés público la protección de las cuencas hidrográficas de Cajamarca, y catalogó el proyecto minero como inviable. (“Gobierno regional ordenó intangibilidad de las cuencas en Cajamarca”3, 2011). El gobierno peruano, a través del nuevo jefe del Gabinete Ministerial, manifestó que el Ejecutivo presentaría una demanda inconstitucional contra la ordenanza del gobierno regional de Cajamarca al señalar que el presidente regional "no tenía autoridad" para tomar esa decisión (“Ejecutivo llevará Conga al TC y evalúa denuncia a autoridades"", 2011).

\footnotetext{
${ }^{3}$ Noticia periodística en diario La República.

${ }^{4}$ Noticia periodística en diario La República.
} 


\section{Reacciones de Yanacocha:}

1. En entrevista con un canal de televisión de Lima, el vicepresidente legal Newmont Sudamérica anunció que la compañía denunciaría judicialmente la ordenanza emitida por el Gobierno Regional.

2. A través de un comunicado desde su sede en Denver (EEUU) difundido en el diario El Comercio, el presidente ejecutivo de Newmont insistió que el Estudio de Impacto Ambiental (EIA) cumplió todos los estándares que exige el país.

3. En un comunicado difundido en los medios, el gerente general, felicitó los acuerdos de la mesa de diálogo y agregó que Newmont estaría a la espera de los resultados del peritaje internacional.

- $\quad$ En febrero de 2012 se inició el peritaje internacional a cargo de 3 peritos extranjeros. En ese mismo periodo, la empresa lanzó una campaña mediática a nivel nacional para elogiar los aportes de la empresa al desarrollo de Cajamarca; la campaña prestó más atención al público limeño que al Cajamarquino. En respuesta a la campaña, los pobladores iniciaron una marcha en defensa del agua. Los manifestantes encabezados por Marco Arana llegaron hasta Lima y realizaron una protesta pública en una plaza central (San Martín).

Como parte de la campaña, produjo y difundió un documental de 20 minutos vía la señal cerrada de televisión (canal "N") y su canal de Youtube. El material audiovisual fue criticado en algunos blogs, por ejemplo, el influyente blog La Mula, el cual consideró que el documental ignoraba los temas más cuestionados por la población. (Sociedad Peruana de Derecho Ambiental [SPDA], 2012).

\section{Reacciones de Yanacocha:}

1. La empresa realizó una conferencia de prensa en Cajamarca y resaltó que el proyecto no afecta los recursos hídricos del departamento.

2. En Lima, Yanacocha se reunió con la prensa extranjera y reafirmó que continuaría el proyecto Conga. "Vamos a gastar el último sudor que 
tengamos, el último esfuerzo de energía para sacar el proyecto", señaló el Gerente General Carlos Santa Cruz ("Newmont sobre Conga: "Vamos a gastar el último sudor que tengamos para sacar el proyecto" ${ }^{5}, 2012$ )

- $\quad$ El 17 de abril, mientras el proyecto seguía suspendido, los Ministros de Ambiente, Agricultura y Energía y Minas dieron a conocer el informe final de peritaje que destacaba que no había destrucción de las cuatro lagunas y que dos que inicialmente serían usadas como desmonte podrían ser sustituidas por reservorios.

Al tercer día de este anuncio, el gobierno hizo saber que el proyecto Conga seguiría solo si Yanacocha aceptaba las nuevas recomendaciones del informe pericial. Al día siguiente, la empresa, a través de un comunicado a la opinión pública, afirmó que evaluaría el anuncio del gobierno. La población cajamarquina consideró la declaración de Yanacocha como un desafío al gobierno e inició nuevas protestas, las mismas que duraron casi un mes y paralizaron la actividad comercial en el departamento.

\section{Reacciones de Yanacocha:}

3. En una entrevista telefónica desde su sede en Denver (EEUU) difundido en el diario El Comercio, por primera vez, el presidente ejecutivo de la empresa Newmont sugirió que el proyecto podría cancelarse. "La inversión en el proyecto Conga terminaría y se trasladarían a otros países" ("Inversión de Conga irá a otros países si cambios no hacen rentable el Proyecto"\%, 2012).

1. Dos semanas después, el gerente de la empresa Buenaventura, expresó un mensaje contrario al 1 presidente de Newmont y señaló que quien evalúa el informe de peritos, no es Newmont, sino todo un equipo de ingeniería de Yanacocha. Fue en entrevista a un diario de Lima.

\footnotetext{
${ }^{5}$ Noticia periodística en diario El Comercio.

${ }^{6}$ Noticia periodística en diario El Comercio.
} 
- Dos meses después, en respuesta al informe pericial, la empresa aceptó el pedido gubernamental y se comprometió a invertir 102 millones de dólares adicionales en el departamento para responder a los nuevos requerimientos. Esa cifra se sumaba a los 4.800 millones de dólares de inversión inicial que la corporación matriz Newmont había hecho en Perú (la cifra más grande en los casi 90 años de existencia de Newmont) (Minera Yanacocha S.R.L., 2011, párr. 20). El presidente de Yanacocha afirmó que la compañía estaba dispuesta a “revisar [la situación] y todos los errores cometidos en el pasado... y tenía la mejor disposición de mirar el pasado para corregir" ("Newmont está dispuesta a corregir errores, afirmó su vicepresidente"7, 2012).

\section{Reacciones de Yanacocha:}

1. En una entrevista con un diario de Lima, el Gerente de Buenaventura culpó al gobierno central y el gobierno regional por el conflicto social. Consideró que el gobierno central no respalda ni hace respetar los permisos formales del proyecto Conga aprobados por el MINEM el 2010.

2. El gerente general, en una entrevista con un canal de televisión de Lima, aseguró que en un plazo de 18 a 24 meses la empresa terminará de construir dos reservorios de agua para el proyecto Conga.

- Al iniciar el mes de julio, la empresa anunció la construcción de un reservorio de agua en la provincia de Celendín. El anuncio fue recibido con protestas de la población, nuevas paralizaciones del comercio y con bloqueo de carreteras. Los días 3 y 4 de julio se produjeron nuevos enfrentamientos de los pobladores con la policía que dejaron 4 civiles muertos y 118 heridos, incluidos policías. Estos hechos hicieron que la Comisión Internacional de Derechos Humanos de la OEA expresara, a través de un comunicado, "su preocupación por las muertes y por la violencia ocurrida en Cajamarca" y pedía al estado "garantizar la vida, la integridad y la seguridad de las personas que protestan contra el proyecto minero Conga” (Comisión Interamericana de Derechos Humanos [CDHI], 2012).

\footnotetext{
${ }^{7}$ Noticia periodística en diario El Comercio.
} 
El 3 de julio, el gobierno declaró por segunda vez el estado de emergencia en las provincias de Celendín, Cajamarca y Hualgayoc. El conflicto Conga había dejado de ser un problema social y se extendía al espectro político por la intervención del presidente de la República y algunos de sus ministros, quienes se pronunciaron constantemente sobre el problema.

En busca de ayudar a la solución del conflicto, el presidente de la República designó a dos líderes de la iglesia católica, Monseñor Miguel Cabrejos y Gastón Garatea, como facilitadores del diálogo entre Yanacocha y las comunidades cajamarquinas. La empresa y autoridades locales no pusieron reparos a la decisión del gobierno.

El 23 de agosto, entretanto, juramentó un nuevo gabinete ministerial, y así por tercera vez, el presidente del Consejo de Ministros tendría la responsabilidad de encontrar una solución al conflicto social en Cajamarca.

\section{Reacciones de Yanacocha:}

1. El gerente general, en una entrevista con un diario de Lima, expresó su deseo de reunirse con los religiosos con el ánimo de solucionar conflicto social con pobladores de Cajamarca.

2. Representantes de la empresa se reunieron con los facilitadores del diálogo. En dicha cita, el gerente general expresó que Yanacocha cumplirá con la propuesta del agua primero, y reiteró que están dispuestos a mejorar su relación con el pueblo de Cajamarca.

3. Por su lado, el presidente ejecutivo de Newmont, en una entrevista telefónica desde su sede en Denver (EEUU) difundido en el diario El Comercio, aseveró que el proyecto Conga seguiría en los planes de la corporación, solo si cuenta con el apoyo de autoridades locales y nacionales.

- $\quad$ En la tercera semana de agosto, el diario El Comercio difundió una encuesta de opinión sobre el caso Conga en la que se conoció que el $78 \%$ de cajamarquinos se oponía al proyecto. El $83 \%$ de estas respuestas pertenecían a 
encuestados de la zona rural de Cajamarca. La población persistió en mostrar su oposición por viabilidad de proyecto y pese al estado de emergencia continuaron las protestas, pero de manera pacífica.

En esas circunstancias, el 23 de agosto, el presidente del Consejo de Ministros anunció en Lima que la empresa suspendía el proyecto Conga indefinidamente. La empresa Newmont se pronunció respecto al anuncio señalando que, si bien el proyecto se suspendía, aún seguía en sus planes de explotación.

El estado de emergencia se mantuvo hasta el 6 de setiembre de 2012.

El anunció calmó en algo las protestas sociales en Cajamarca y ayudó a que la actividad comercial en el departamento comenzara a normalizarse.

Entretanto, en los alrededores del proyecto los pobladores se organizaron y crearon grupos para resguardar las lagunas adyacentes a la mina. Sus miembros se autodenominaron "guardianes de la laguna".

\section{Reacciones de Yanacocha:}

1. El presidente ejecutivo de Newmont, en una entrevista a un diario extranjero desde su sede en Denver (EEUU) difundido por el diario El Comercio, aseveró que no hay un entorno favorable para el desarrollo de proyecto Conga. "La clave en este momento es lograr la aceptación de las partes que son impactadas por Conga" ("Newmont: en estos momentos no existe condiciones para proceder Conga ", 2012).

2. En entrevista a diario capitalino, gerente de Buenaventura resaltó que paralización de proyecto dejaría sin empleo a 4500 personas.

- Los efectos de la suspensión indefinida de Conga en la empresa no tardaron: el 96\% de los empleados fueron despedidos. Se cancelaron todos los contratos de servicios con los subcontratistas. Los más afectados fueron los pequeños y medianos proveedores locales, con el consiguiente golpe a la economía local.

${ }^{8}$ Noticia periodística en diario El Comercio. 


\section{Reacciones de Yanacocha:}

1. A través de un diario local en Cajamarca, el vicepresidente regional de recursos humanos de Yanacocha afirmó que los despidos de empleados y la reducción del número de proveedores se deben a disminución en producción minera.

2. Ante un diario local en Cajamarca, el gerente del proyecto Conga, invitó a los periodistas a visitar instalaciones de yacimiento Conga y constatar que el proyecto está paralizado y solamente se construyen los reservorios de agua.

3. En un comunicado de prensa difundido por los medios nacionales, la empresa Yanacocha anunció que a partir del año 2013 otra persona ocuparía la gerencia general.

La decisión de la suspensión de Conga fue como la crónica de una muerte anunciada. El proyecto, desde agosto de 2012, sigue paralizado a la fecha. Nadie sabe sí se reanudará algún día.

Con los nuevos gobiernos en el país Ollanta Humala (2011-2016), Pedro Pablo Kuczynski (2016-2018) y Martín Vizcarra (marzo del 2018 al presente), la mina Conga no da visos de reapertura. A la fecha del término de este trabajo académico, el proyecto se mantenía con 19 trabajadores en planilla y otros 120 como personal subcontratado (mediante nueve empresas contratistas).

La empresa Yanacocha continúa presente en Cajamarca y está planeando expandirse a otras operaciones mineras hasta el año 2040, de acuerdo con un boletín informativo de la compañía de 2019 (Minera Yanacocha S.R.L., 2019). 


\subsection{Evolución de la crisis: resumen gráfico}

Figura 1.

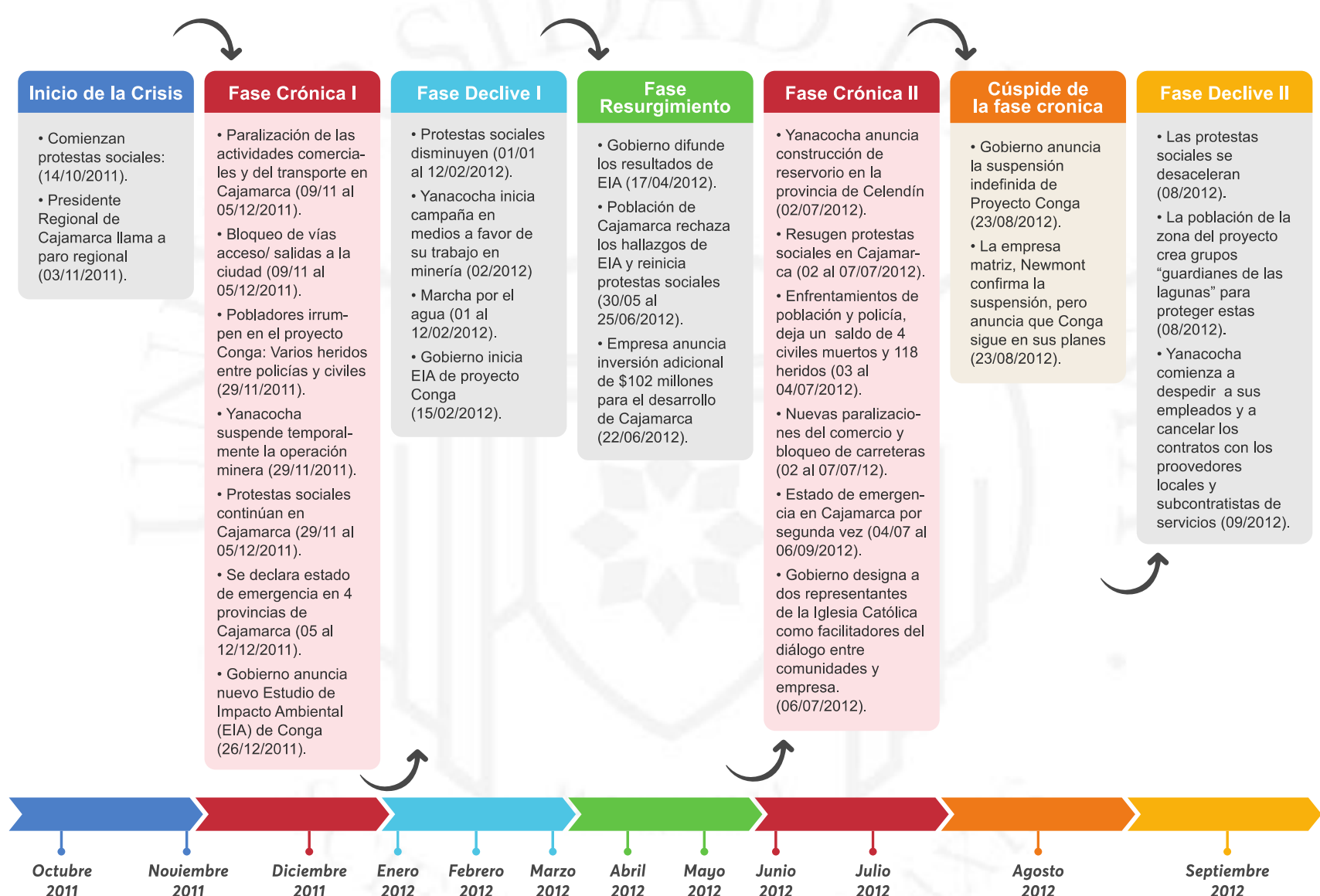

Fuente: Elaboración propia con base a la información periodística de octubre 2011 a octubre 2012. 


\subsection{Actores centrales de la crisis:}

- Minera Yanacocha (desde su propia mirada):

\begin{tabular}{|c|c|}
\hline Interés: & $\begin{array}{ll}\text { - } & \text { Desarrollar sin obstáculos el proyecto Conga. } \\
\text { - } & \text { Conseguir la aceptación (licencia social) de la población. } \\
\text { - } & \text { Conseguir que gobierno y población legitimasen el Estudio de } \\
\text { Impacto Ambiental (EIA). }\end{array}$ \\
\hline Autopercepción: & $\begin{array}{l}\text { - } \quad \text { Empresa responsable con la población y el medio ambiente. } \\
\text { - } \quad \text { Gran contribuyente al desarrollo de Cajamarca y del país }\end{array}$ \\
\hline $\begin{array}{l}\text { Percepción sobre } \\
\text { actores locales y } \\
\text { nacionales }\end{array}$ & $\begin{array}{l}\text { - Líderes comunales: Solo buscan beneficios personales. Son } \\
\text { causantes de los actos de violencia. } \\
\text { - Líderes de la iglesia Católica: Conciliadores entre la empresa, } \\
\text { el gobierno y las comunidades locales. } \\
\text { - Gobierno Peruano: Principal aliado. Pero ante la poca } \\
\text { aceptación del proyecto en la población de Cajamarca, lo } \\
\text { culpabilizo por no hacer respetar aprobación de EIA en } \\
\text { ejecución de proyecto. } \\
\text { Gobierno Regional: Su presidente (Gregorio Santos) es el } \\
\text { mayor detractor de la empresa y manipulador de la población } \\
\text { para obtener beneficios personales. } \\
\text { Grupos de la sociedad civil, como el Frente de Defensa } \\
\text { Ambiental de la provincia de Cajamarca, Frente de Defensa } \\
\text { de los Interés de Cajamarca, Comando Unitario de Lucha, y } \\
\text { ONG Grufides: Enemigos del desarrollo minero. Dirigen las } \\
\text { protestas. } \\
\text { Prensa local: Parcializada con los opositores al proyecto. No } \\
\text { destacan los puntos de vista de la empresa. } \\
\text { Prensa nacional: Desinformada, solo replica lo que difunden } \\
\text { los medios locales; con excepción tal vez del grupo de medios } \\
\text { El Comercio. } \\
\text { Pobladores cajamarquinos: Desinformados y manipulables } \\
\text { por los líderes anti mineros. Inventan argumentos de que la } \\
\text { empresa puede destruir todos los recursos hídricos. } \\
\text { Cámara de Comercio de Cajamarca: Aliado }\end{array}$ \\
\hline
\end{tabular}

Fuente: Elaboración propia con base al cuadro Conflictividad Socioambiental en la Región de Cajamarca (Bedoya y Puma, 2016). 
- Poder Ejecutivo

\begin{tabular}{|l|l|}
\hline Interés: & $\begin{array}{l}\text { Apoyar al proyecto Conga; pero no quedar mal ante la } \\
\text { población de Cajamarca que creyó en su discurso de "primero } \\
\text { el agua" y por eso votó en las elecciones presidenciales del año } \\
2011 \text { por el candidato Ollanta Humala. }\end{array}$ \\
\hline Autopercepción: & $\begin{array}{l}\text { Gobierno decidido a impulsar la economía mediante la } \\
\text { inversión privada y a mejorar la calidad de vida de sus } \\
\text { ciudadanos. } \\
\text { Conciliador frente protestas públicas en contra de } \\
\text { Yanacocha. }\end{array}$ \\
\hline $\begin{array}{l}\text { Percepción sobre la } \\
\text { empresa }\end{array}$ & - Dispuesta por invertir en el país. \\
\hline
\end{tabular}

Fuente: Elaboración propia con base al cuadro Conflictividad Socioambiental en la Región de Cajamarca (Bedoya y Puma, 2016).

- Gobierno Regional de Cajamarca.

\begin{tabular}{|l|l|}
\hline Interés: & $\begin{array}{l}\text { Exigir que el Gobierno Peruano invalide ejecución de } \\
\text { proyecto Conga. } \\
\text { Retirar definitivamente de Cajamarca a empresa minera } \\
\end{array}$ \\
$\begin{array}{l}\text { Yanacocha. } \\
\text { Que el gobierno escuche los reclamos del pueblo } \\
\text { cajamarquino. }\end{array}$ \\
\hline Autopercepción: & $\begin{array}{l}\text { Entidad responsable de cuidar medio ambiente de la región y } \\
\text { no permitir ninguna explotación minera en cabeceras de } \\
\text { cuencas hidrográficas. }\end{array}$ \\
\hline Percepción sobre & $-\begin{array}{l}\text { Responsable por daños ambientales en la ciudad de } \\
\text { la empresa } \\
\text { Incumplió promesas y engaño a población de Cajamarca. }\end{array}$ \\
\hline
\end{tabular}

Fuente: Elaboración propia con base al cuadro Conflictividad Socioambiental en la Región de Cajamarca (Bedoya y Puma, 2016). 
- Municipalidades distritales con más presencia en el conflicto (Huasmín, Sorochuco, La Encañada y Bambamarca).

\begin{tabular}{|c|c|}
\hline Interés: & $\begin{array}{l}\text { - Exigir que Yanacocha no dañe sus fuentes de agua } \\
\text { (lagunas: Perol, Azul, Mala y Chica). } \\
\text { - Ser escuchados por el Estado Peruano. } \\
\text { - Que Yanacocha retire definitivamente maquinaria y } \\
\text { empleados de yacimiento Conga. }\end{array}$ \\
\hline Autopercepción: & $\begin{array}{l}\text { - Responsable de escuchar y proteger medio ambiente } \\
\text { y fuentes de agua de sus pobladores. }\end{array}$ \\
\hline $\begin{array}{l}\text { Percepción sobre la } \\
\text { empresa }\end{array}$ & $\begin{array}{ll}\text { - } & \text { Mintió a toda la población. } \\
\text { - } & \text { Incumplió promesas. } \\
\text { - } & \text { Causo daños en medio ambiente. }\end{array}$ \\
\hline
\end{tabular}

Fuente: Elaboración propia con base al cuadro Conflictividad Socioambiental en la Región de Cajamarca (Bedoya y Puma, 2016).

- Grupos de la sociedad civil de Cajamarca (Frente de Defensa Ambiental de la Provincia de Cajamarca; Frente de Defensa de los Intereses de Cajamarca, Asociación Civil Plataforma Interinstitucional Celendina, Comando Unitario de Lucha, y ONG Grufides).

\begin{tabular}{|l|ll|}
\hline Interés: & $\begin{array}{l}\text { No permitir la explotación de las fuentes naturales de } \\
\text { agua. }\end{array}$ \\
& $\begin{array}{l}\text { Abogar por la inviabilidad del proyecto Conga. } \\
\text { Autopercepción: }\end{array}$ & $\begin{array}{l}\text { Protector de los recursos naturales de Cajamarca. } \\
-\end{array}$ \\
& $\begin{array}{l}\text { Abanderado de los derechos de los grupos socialmente } \\
\text { vulnerables. }\end{array}$ \\
\hline $\begin{array}{l}\text { Percepción sobre la } \\
\text { empresa }\end{array}$ & $-\begin{array}{l}\text { No le interesa el desarrollo de Cajamarca sino solo el } \\
\text { provecho empresarial propio. } \\
\text { No es sensible a los derechos de la población } \\
\text { Contamina el agua. }\end{array}$ \\
\hline
\end{tabular}

Fuente: Elaboración propia con base al cuadro Conflictividad Socioambiental en la Región de Cajamarca (Bedoya y Puma, 2016). 


\section{CAPITULO III: ANÁLISIS DE LA CRISIS}

Luego de elaborar un registro del manejo comunicacional de la crisis de Conga, realizamos un análisis sobre la efectividad de las respuestas y acciones de Yanacocha a la luz de lo que sugieren las buenas prácticas en gestión de crisis:

\section{Dar la cara:}

Salir al frente de los hechos y comunicar cara a cara los mensajes de la empresa es la primera recomendación para manejar una crisis, y con ello coindicen todos los expertos. Esta fue la estrategia más ausente en el manejo de la crisis de Conga. El no salir "ante las cámaras" y, en su lugar, optar por difundir los puntos de vista corporativos a través de comunicados de prensa. Esto dio un mensaje de indiferencia ante el conflicto social que estaba agudizándose y que derivó en la crisis.

En el período de doce meses en que se centra este trabajo, la aparición de la empresa, en forma presencial, ante la prensa local -fuente principal de las noticiasocurrió solo en una ocasión: en enero de 2012, cuando encabezó una conferencia de prensa con periodistas cajamarquinos en la capital de dicha región. Adicionalmente a esa, otra aparición ante periodistas en forma grupal fue en marzo 2012 cuando la empresa dialogó con la Asociación de Prensa Extranjera Acreditada en Perú, en la ciudad de Lima.

Yanacocha intentó cubrir esta ausencia ofreciendo entrevistas uno a uno a determinados medios locales y nacionales cuando se iniciaron las protestas y bloqueos de vías en octubre del 2011. Cuando el conflicto empezó a agudizarse: conforme la crisis crecía, la empresa se contactaba y ofrecía entrevistas individuales (uno a uno) a la prensa.

A partir del 2012, las entrevistas solo fueron con los medios de la capital. La prensa local no fue atendida.

\section{Manejar la crisis desde lejos y sin aprovechar información de primera mano:}

Una forma de restar fuerza a la gestión de crisis es manejarla desde lejos (desde las oficinas) y confiando en la información de una sola fuente (la de casa). Este es otro error en el que incurrió Yanacocha al tomar las decisiones respecto a la crisis desde Lima, 
donde se encuentra su sede central y están todos quienes toman decisiones. Sucedió lo mismo con la empresa Newmont (accionista mayoritario de Yanacocha) cuando desde su sede central en Denver (Estados Unidos) daba a conocer algunas declaraciones y decisiones frente a lo que sucedía en Cajamarca.

Ante una crisis, una empresa que sabe cómo manejar una situación difícil suele usar dos recursos que le permitirán conocer y recoger la información de los stakeholders, sobre todo de los grupos críticos. Por la actuación de Yanacocha, vemos que la compañía no aprovechó estos recursos.

- Información de primera mano de los grupos de interés, en este caso de la comunidad cajamarquina afectada por Conga. Yanacocha poco hizo por escuchar la voz de los grupos que expresaban abiertamente sentirse afectados por el proyecto minero. La propia comunidad así lo manifestaba por diversos canales, pero la compañía ignoró la posición de los pobladores. Por esto, al sentirse desatendidos, se oponían cada vez más a Conga.

La comunidad cajamarquina manifestaba su insatisfacción por el proyecto minero y en respuesta solo recibía de la empresa comunicados con un lenguaje técnico que no siempre lograba entender. Esto hacía que los pobladores se sientan engañados.

- Canales propios creados por la empresa para informar sobre el problema. La poca información que difundió Yanacocha durante el conflicto fue transmitida mediante su sitio web o a través de entrevistas individuales que los ejecutivos ofrecían al principal periódico Cajamarquino (Panorama Cajamarquino) o a los principales periódicos de Lima (diario El Comercio, por ejemplo).

El único canal que uso Yanacocha en medios sociales fue YouTube. Sin embargo, este espacio funcionaba como un repositorio donde se colocaban videos con intereses corporativos y no daba paso a la interacción con los internautas. Por ejemplo, en el video sobre la movilización de los trabajadores a favor del proyecto Conga no se vio ninguna respuesta de la compañía a lo expresado por los cibernautas. Esto indicaría la indiferencia de Yanacocha por lo dicho por la gente. 


\section{Brindar mensajes tardíamente y con contenido confuso:}

El manejo comunicacional de la crisis se caracterizó por las respuestas reactivas de la empresa. Yanacocha esperaba a que los otros actores de la crisis se expresen, sea mediante reclamaciones o acciones, para recién dar a conocer su posición.

Esto se tradujo en mensajes corporativos fuera de tiempo para la población. La comunidad cajamarquina se enteraba de la posición de Yanacocha o del conflicto mediante los mensajes continuos que recibía de dirigentes comunales o religiosos, las autoridades del gobierno local, las ONG, entre otros actores. Es decir, parecía que a la empresa le gustaba llegar en segundo lugar, en términos de gestión comunicacional.

Uno de los altos ejecutivos de Yanacocha, entrevistado para este trabajo, admite este manejo reactivo:

"Realizamos una comunicación básicamente reactiva, [las comunidades u opositores al proyecto minero] decían algo y nosotros salimos a contestar. No tuvimos tiempo o no supimos manejar el hecho sobre salir a proponer también algunos mensajes y tratar de influir en la agenda. Era complicado, pero debimos hacerlo” (R, Del Aguila, gerente de comunicaciones de la empresa Yanacocha, [Comunicación personal], 18 de julio, 2019)9

Por otro lado, la estrategia que desplegaba Yanacocha tampoco evidenció una línea de coordinación de los mensajes que emitían los directivos en el Perú y en Estados Unidos. En la evolución de la crisis de Conga se pudo identificar que hubo momentos en que los ejecutivos de Yanacocha y de Newmont brindaban mensajes en direcciones contrarias.

\section{No reconocer los errores y culpar a otros por la crisis:}

Durante y después del conflicto -incluso en la actualidad- Yanacocha consideró que la crisis de Conga se desató por tres razones: la cobertura informativa exagerada y

\footnotetext{
${ }^{9}$ Entrevista personal a gerente de comunicaciones de la empresa Yanacocha el 18 de julio de 2019.
} 
sesgada de la prensa; las reacciones del Gobierno Regional de Cajamarca; y la falta de decisión del Gobierno central durante los años en que se dio el conflicto. ${ }^{10}$

La empresa no reconoció que la desconfianza de la población cajamarquina hacia el proyecto minero se originó debido a la falta de comunicación directa con los grupos de interés, a la escasez de información clara y comprensible para los pobladores y, en general, a la falta de atención sobre el sentir de la población. Asimismo, la empresa no tomó en cuenta los antecedentes negativos de las cinco crisis previas en las que fue un actor central ni tuvo en cuenta el rol de los pobladores de la zona de influencia del proyecto durante el desarrollo de estas.

La posición de Yanacocha fue que los pobladores eran influenciados negativamente por las autoridades locales de Cajamarca y las ONG y esto provocó sentimientos de animadversión hacia el proyecto minero.

Apenas unos meses antes del cierre del proyecto, en junio de 2012, la empresa vio que era oportuno acercarse a las comunidades y reconstruir las relaciones con los diferentes grupos de la sociedad civil.

En el mismo sentido, Yanacocha indicó que la prensa local agudizó el conflicto porque "no suele estar bien informada ni le interesó estar informada", mientras que la prensa nacional tampoco estuvo interesada en informarse correctamente de los hechos. ${ }^{11}$ Sobre esto último (prensa nacional) podemos decir que sí hay asidero para este argumento, pues durante la crisis los periodistas en Lima no estaban bien informados sobre la situación real que se vivía en Cajamarca. Muchos repetían e informaban de forma superficial, sin investigar, contrastar o revisar varias fuentes.

En cuanto al impacto ambiental del proyecto en Cajamarca, la compañía nunca reconoció la envergadura del impacto de la mina en los recursos naturales de la región. Solamente aceptó de forma parcial cierta responsabilidad en el proyecto cuando fue

\footnotetext{
${ }^{10}$ Observación hecha con base a la entrevista a gerente de comunicaciones de la empresa Yanacocha realizada el 18 de julio de 2019 para esta tesis, y declaraciones del presidente de Buenaventura al diario El Comercio el 26 de junio de 2012.

${ }^{11}$ Entrevista personal a gerente de comunicaciones de la empresa Yanacocha el 18 de julio de 2019, para fines de este trabajo.
} 
obligada a atender las recomendaciones del Estudio de Impacto Ambiental (EIA) ordenado por el gobierno central en abril de 2012.

\section{Subestimar el poder de influencia de la población local:}

En una crisis, una empresa no puede subestimar el poder de influencia que tiene la ciudadanía en el desarrollo del negocio. Esto es un error en el que incurrió Yanacocha al restar importancia a las protestas de la población, los líderes comunales, el Gobierno Regional de Cajamarca y grupos de la sociedad civil, quienes mediante sus discursos y acciones hicieron sentir su voz ante los medios más que la voz de la empresa; así, desde un inicio lograron deslegitimar el Estudio de Impacto Ambiental (EIA) que realizó la compañía en cumplimiento a las leyes.

Yanacocha desde el inicio del conflicto se resistió inexplicablemente a identificar el discurso que circulaba entre sus grupos de interés y, de este modo, se negó ella misma -voluntariamente o no- a disipar las dudas de la población en torno al proyecto minero. La compañía tenía todas las capacidades a la mano para manejar el conflicto desde un inicio, pero no se animó a leer el mensaje de la población cajamarquina: como recuerda el diario El Comercio 7 de cada 10 cajamarquinos se oponían al proyecto minero según un sondeo público.

Con los antecedentes que había afrontado Yanacocha en el pasado, la empresa no debió pasar por alto a la población. Al contrario, sus esfuerzos debieron enfocarse en convertir a la población en un aliado de la empresa para asegurar el desarrollo del proyecto minero.

Por otra parte, la compañía tampoco sopesó la influencia de los medios locales en la población cajamarquina cuando comenzó la crisis de Conga. Frente al discurso de los opositores que se reproducía continuamente en los medios de prensa local, Yanacocha debió tener un rol más activo para anular el efecto de los mensajes que promovían el rechazo a la ejecución del proyecto minero.

Otro ejemplo de cómo la empresa se resistió a creer en el poder de influencia de la población fue cuando mostró su poca disposición para aceptar entrevistas con la prensa local. A medida que la crisis escaló, Yanacocha optó por emitir su posición a través de 
comunicados difundidos en la prensa nacional, ignorando la influencia de los medios cajamarquinos en la población.

Al no ser atendidos por la empresa en sus requerimientos de entrevistas, a los medios de comunicación de Cajamarca no les quedaba otra opción que hacer eco a los mensajes de la población, y así los medios se convirtieron en una herramienta fundamental para los grupos opositores porque les brindaba un espacio para transmitir sus mensajes.

\section{Hacer "demostraciones de fuerza":}

Como consecuencia de lo anterior, el mensaje que Yanacocha parecía estar dejando ante la población durante el conflicto fue que era una empresa minera poderosa que no necesitaba dialogar con la población. En forma consciente o no, la compañía apeló a su grado de superioridad y consideró que la oposición de la población cajamarquina no podía afectar el desarrollo del proyecto.

Un ejemplo de estas demostraciones de superioridad fue la marcha de empleados que organizó el 19 de octubre de 2011 por las principales calles del centro de Cajamarca, con la intención de enviar un mensaje que todos los empleados estaban unidos con la alta dirección a favor del proyecto minero. La superioridad se notó más cuando Yanacocha incorporó en su canal de YouTube un video con la leyenda "Por sí alguna duda quedó sobre cantidad de gente que marchó por la paz el diálogo y el desarrollo”. Esta acción, lejos de ayudar a fortalecer su imagen y confianza con todos sus grupos de interés, lo empeoró.

De otro lado, cuando se inició el peritaje al segundo estudio de Impacto Ambiental (EIA) al comenzar el año 2012, Yanacocha decidió lanzar una campaña informativa en los medios a nivel nacional, con énfasis en Lima, que se centró para dar a conocer los aportes de la compañía al desarrollo de Cajamarca. Por el alcance de la campaña, esta acción apuntaba a reconstruir la imagen de la empresa ante opinión pública limeña más que a reconstruir la relación con la población cajamarquina. Sin embargo, como observó en ese tiempo el influyente blog "La Mula", el propósito de la empresa con esta campaña no se cumplió. "El documental no toma en cuenta el tema del peritaje al Estudio de Impacto Ambiental, los reclamos de los opositores, o los posibles daños ambientales que 
traería consigo la desaparición de lagunas en la zona" (Sociedad Peruana de Derecho Ambiental [SPDA], 2012).

En respuesta, la población cajamarquina inició una marcha hasta Lima en defensa del agua. La campaña lejos de favorecer la imagen corporativa de Yanacocha, la debilito aún más.

\section{Vocero débil:}

En tiempos de crisis, el rol del vocero corporativo es esencial para el manejo de estas situaciones. El vocero es la voz visible que hará que el mensaje de la empresa sea creíble o no. Como hemos visto, Yanacocha no supo sacar provecho a este rol durante todo el ciclo de la crisis porque la figura del vocero pocas veces fue visible. Los voceros aparecieron ocasionalmente en los medios y cuando lo hicieron no lograron transmitir mensajes sustanciales (que respondieran a las interrogantes y cuestionamientos de la población) ni creíbles para sus grupos de interés. Las respuestas tardías en boca de los voceros debilitaron el rol de estos ante los actores de la población local afectados en la crisis.

Asimismo, los voceros aportaron poco en el manejo de la crisis debido a que la empresa, en unos casos, no unificaba su mensaje oficial, y en otros, cuando emitía algún mensaje, lo hacía de forma reactiva y usando un lenguaje poco empático con los stakeholders. Hemos leído en páginas anteriores por ejemplo la opinión del gerente general de la empresa, en octubre de 2011, cuando fue entrevistado al término de la marcha de empleados a favor de proyecto: el reconocía por primera vez la necesidad de dialogar con las comunidades, pero, al mismo tiempo, negaba que haya existido problemas de contaminación ambiental a causa de las operaciones mineras de la compañía 


\section{CAPITULO IV: MARCO CONCEPTUAL}

\subsection{Las organizaciones en la era de la transparencia: Rol de los stakeholders}

El entorno de creciente monitoreo ciudadano que ahora rodea a las organizaciones eleva los riesgos de que sean objeto de las conversaciones o estén en el centro de las noticias y así están más expuestas a enfrentar situaciones de crisis de diversos niveles.

Vivimos en la llamada "sociedad de la transparencia" a las organizaciones les es cada vez más difícil alejarse de los comentarios públicos y, peor aún, esconder algún mal proceder....[ahora] las personas tienen la potestad de hablar sobre cualquier asunto, difundir información o denunciar cualquier hecho sin tener que solicitar autorización a alguien (Sheen, 2012, p. 4).

Los canales digitales han elevado el rol del ciudadano que ha pasado de ser un observador pasivo de la realidad a un observador crítico; con poder de informar y emitir juicios positivos o negativos sobre una empresa. Calleja, Paniagua y Victoria (2017) sostienen que "los medios sociales van ganando terreno en nuestras vidas y con la ayuda de ellos los ciudadanos ahora más que nunca se han convertido en agentes activos de la comunicación, en los propios reporteros de la actualidad" (p. 3).

Este entorno presenta aún otro desafío a las organizaciones: el surgimiento de los stakeholders (o grupos de interés, en español), término acuñado en 1984 por el académico Edward Freeman (2010) y que agrupa a las personas en función a su influencia en las organizaciones o a cómo estas últimas impactan en los diversos grupos (p. 53).

El concepto no solo se refiere a quienes tienen alguna relación con una empresa o institución (por ejemplo, los clientes o los empleados) sino a cualquier grupo que impacte de alguna manera en una organización -por ejemplos, jóvenes activistas en las redes sociales- o se vea afectado por las actividades u operaciones de una empresa, por ejemplo, los vecinos o una comunidad rural (Sheen, 2016). En la actualidad el apoyo de los stakeholders es esencial para la supervivencia continúa del negocio (Freeman, 1983). 
Para Escudero (2010), los stakeholder ejercen un poder de influencia considerable sobre las organizaciones debido a su alto nivel de sociabilización con otros grupos. Por ello, las empresas necesitan identificarlos con anticipación y tomarlos en cuenta antes que su inadvertencia afecte al éxito de la organización (p. 40).

Cuando las empresas tienen en consideración a los stakeholders -y no solamente a los clientes- y atienden sus necesidades, los grupos tienden a ver con mejores ojos la actividad empresarial y a confiar en las compañías. Esta confianza, para las empresas cuyo negocio depende directamente de los recursos naturales, le abre las puertas a otro activo intangible de mucho valor hoy en día: la licencia social. Este término refleja la legitimidad y aceptación que una comunidad otorga a las actividades o proyectos de una empresa (Demuijnck \& Fasterling, 2016, pp. 1-2).

Alloza (2019) afirma que los grupos de interés son determinantes para el futuro a largo plazo de las organizaciones al ser ellos los que otorgan el reconocimiento y la legitimidad social para operar (p. 19). Esta legitimidad es un factor fundamental para la imagen de una empresa.

\subsection{La imagen corporativa}

La capacidad de los grupos de interés para fiscalizar a las empresas se ha incrementado en la sociedad de la transparencia y esto exige a las empresas a tener mayor cuidado con lo que hacen y dicen, pues cualquier cosa que hagan o comuniquen puede saltar a la esfera pública y afectar directamente la imagen y supervivencia del negocio (Sheen, 2012).

Capriotti (2013) define el término imagen corporativa como la estructura mental que se va formando en el público cuando las personas procesan toda la información que reciben sobre una organización. Para Argenti (2016) imagen es el compendio de como una organización es percibida por sus grupos de interés en base a su experiencia y opinión de los demás (p. 205).

"La imagen abarca los impactos y logros que una empresa ha alcanzado desde sus inicios, las conductas y relaciones con sus empleados, el sentido de responsabilidad que 
muestra hacia su entorno, las experiencias personales de todos los que se relacionan con la empresa" (Boskurt, 2018, p. 61).

La imagen corporativa es considerada también como un activo intangible, es decir, un recurso que añade valor a las empresas. Según Corporate Excellence-Centre for Reputation Leadership (2020) una correcta gestión de los intangibles entre los que se encuentra la imagen corporativa, asegura un impacto social positivo en el negocio, así como el beneplácito de los grupos de interés. (como se citó en la revista Imagen y Comunicación, N 85, p. 27).

Si este recurso recibe "golpes" mediante comentarios negativos que ponen en duda o enturbian su buen nombre, el golpe repercutirá en el negocio. Para Argenti, por ejemplo, "una mala experiencia con un representante de alguna compañía o una crítica negativa publicada por algún bloguero de gran popularidad puede llegar a destruir la relación con un cliente de por vida". Y bien podríamos agregar que sin clientes no hay negocio.

\subsection{La gestión de crisis en el siglo XXI}

En el presente siglo, con una ciudadanía cada vez más fiscalizadora y con medios digitales al alcance para opinar las 24 horas del día, no es difícil imaginar que, en muy poco tiempo, un problema empresarial pueda convertirse en tema de conversación y de crítica pública y de allí se convierta en una crisis. Según Galecio (2012) "muchas crisis empiezan en las redes sociales, allí se canaliza el descontento de la gente y luego salta a los medios tradicionales" (p. 13).

El termino crisis es definido como "la percepción de un evento impredecible que amenaza las expectativas de los stakeholders y puede afectar seriamente el desempeño de una organización y generar resultados negativos" (Coombs, 2015, p. 3). Son situaciones inesperadas que dañan la imagen de la entidad (p. 2).

Si las organizaciones no reaccionan inmediatamente ante una crisis, correrán el riesgo de perder credibilidad. Para Remy (2015), "es importante identificar la crisis oportunamente, controlar los daños y buscar soluciones de manera integrada...una crisis 
no contenida a tiempo se expande con agresividad y su impacto negativo reduce la capacidad de respuesta a medida que este se intensifica" (p. 59).

Según una encuesta el 93\% de los ejecutivos de la comunicación corporativa a nivel mundial destacan que la gestión de crisis es su responsabilidad primordial y es fundamental para el éxito de la compañía (The Rising Chief Communications Officers VI, 2016).

Los casos de crisis en las últimas décadas sugieren que una gestión integral de crisis debe considerar tanto los factores técnicos (o sea, abordar las causas del problema) como los factores de toma de decisiones (en manos de los líderes de las empresas) y, por supuesto, el factor comunicacional. Remy sostiene que "las comunicaciones en escenarios de crisis son un aspecto crucial. Su buen manejo puede neutralizar o amortiguar el efecto negativo, además de enmarcar de modo adecuado los hechos en la mente de la opinión pública y así contener el daño y acortar su duración” (p. 133).

No existen fórmulas para manejar una crisis porque cada problema es particular a una organización, a un entorno y a un periodo específico. Sin embargo, los expertos en el tema (Gaines-Ross, 2010; Remy, 2015; Argenti, 2016; Hunter, Van \& Besiou, 2017) recomiendan, en base a su experiencia, las siguientes estrategias marco para manejar las crisis desde la perspectiva comunicacional:

- Dar la cara. Todos los expertos coinciden que, en una crisis corporativa, la empresa tiene que dar la cara. Hacer frente a las interrogantes y cuestionamientos que el público hace a la compañía, enviar un mensaje implícito de que la empresa no huye y está dispuesta a asumir sus responsabilidades, si es que las tiene.

- Asumir la responsabilidad de los hechos y no evadir responsabilidad. Si la organización que es objeto de la crisis tiene responsabilidad de los hechos, tiene que asumirlos. Evadir las responsabilidades, sea con un lenguaje impreciso o negándose aparecer frente la opinión pública transmite un mensaje de falta de honestidad. Si la empresa no es responsable, igualmente tiene que salir "ante las cámaras" y mostrar los argumentos de su inocencia. 
- No hacer demostraciones de fuerza. En situaciones de crisis, la opinión pública se pone de lado de los más débiles (que son las víctimas o los afectados por el problema), y cuestiona a quien tiene más poder, que suelen ser las empresas (si la crisis involucra a dos empresas, la organización más pequeña es la que suele recibir el beneficio de la duda del público). Por tanto, lo que tiene que evitar una empresa es hacer sentir su superioridad ante los demás, aun cuando no sea culpable de los hechos, porque el mensaje que suele formarse en la opinión pública es el de "Goliat" queriéndose imponer sobre "el David” débil y afectado.

- Mostrar empatía con los grupos de interés afectados por la crisis. Independientemente de la responsabilidad de la organización en una crisis, los voceros de la empresa no solo tienen que decir mensajes sino mostrar empatía con los afectados, de tal modo que este sentimiento se vea genuino. Aquí tanto las palabras como el lenguaje no verbal cuentan mucho para expresar los sentimientos de solidaridad y acompañamientos a los afectados en esos momentos difíciles.

- Subestimar a los grupos de interés. El principal insumo para concebir los mensajes corporativos y tener una respuesta certera para el manejo de la crisis es la opinión de los grupos de interés frente a los sucesos del conflicto. No hacer seguimiento a esa opinión y a cómo va variando el sentir de los afectados, representa un alto riesgo para la empresa porque sus mensajes no van a atender lo que los stakeholders afectados quieren y deben escuchar. Peor aún será ignorar el poder de influencia que estos grupos de interés tienen en las fuentes que forman opinión en el público, es decir en los medios de comunicación y en las redes sociales. 


\section{CONCLUSIONES}

1. La gestión de la comunicación en el caso Conga reveló una falta de preparación y planificación de la empresa para manejar una crisis del nivel que le tocó afrontar. Uno de los aspectos por el que se recuerda el incidente es la ausencia de respuestas de la empresa.

Durante el conflicto, la estrategia que más uso la empresa fue el silencio. Yanacocha prefirió callar conforme los hechos escalaban, y cuando salió a comunicar algo lo hizo de forma reactiva y tardía. Los voceros, con frecuencia, prefirieron los comunicados de prensa antes que salir presencialmente y responder las preguntas de los medios masivos.

2. La compañía mostró carencias en las estrategias de relacionamiento con la población local a largo plazo, desde un inicio y en momentos de calma. La empresa arrastraba antecedentes negativos para generar confianza en la población, pero parece que sus líderes no aprendieron las lecciones que le dejaron las crisis previas.

Las comunidades locales sentían recelo hacia la actividad minera por los hechos pasados tales como la compra de terrenos a precios subvaluados, el derrame de mercurio en Choropampa o la construcción de un reservorio en el centro poblado de Combayo. Así, para la población cajamarquina que se dedicaba a la agricultura y ganadería, el proyecto Conga era una actividad que nuevamente ponía en riesgo sus fuentes de supervivencia, como el agua.

Si la empresa consideraba equivocadas estas percepciones debió tomar este problema como una oportunidad para lanzar el proyecto Conga y cambiar de rumbo en su forma de relacionarse con las comunidades.

3. Yanacocha mostró exceso de autoconfianza. Asumió erradamente que, teniendo a su favor a representantes del Poder Ejecutivo, podría manejar el conflicto sin 
mayores problemas, y que el proyecto minero podría seguir adelante, dado el aporte de la gran minería al desarrollo del país en general.

Diríamos que este sentimiento hizo que la empresa viera a los pobladores como actores secundarios en el conflicto (en términos de toma de decisiones) y, al mismo tiempo, le impidió prever que los reclamos sociales podrían desbordarse y con ello se abrirían las puertas al fin del proyecto. En las declaraciones de los accionistas frente a la crisis, el mensaje que utilizaron casi siempre fue "el proyecto sigue en pie", situación que irritaba a los pobladores cajamarquinos pues que los colocaba como un actor irrelevante para el desarrollo de Conga.

Culpar a las autoridades del gobierno local y regional de Cajamarca y a las ONG locales por el conflicto surgido fue uno de los errores más grandes en su intento por aparecer inocente y eficiente ante la opinión pública. Ya hemos repasado que, en estas situaciones, el público se inclina a favor de los grupos de interés afectados. El efecto de trasladar la culpa a los más débiles tuvo un efecto totalmente contrario al deseado.

4. Al manejar en forma reactiva la crisis y al distanciarse de sus grupos de interés clave para el proyecto (los grupos de la sociedad civil y las autoridades locales), la empresa cedió el rol principal en el conflicto a quienes consideraba sus detractores y, de este modo, ayudó a que los mensajes de éstos resonaran más en la opinión pública que los mensajes corporativos. Las quejas reiteradas de tales grupos son las que, con más frecuencia, los medios masivos locales recogieron y transmitieron.

Sin quererlo, Yanacocha se puso en segundo plano en la gestión de esta crisis.

5. Subestimar la voz de los stakeholders directos y, por tanto, no conocer sus expectativas y reclamos fue como un "autogol" para la empresa y esto debilitó mucho su imagen corporativa. Una muestra de la alicaída imagen que se había 'ganado' fue la encuesta de opinión de Ipsos Apoyo 2012, publicada por el diario El Comercio (es decir, a un día de la suspensión de Conga) que indicaba que el $78 \%$ de la población cajamarquina estaba en contra de la decisión de la empresa de continuar con su proyecto estrella. 
Si Yanacocha hubiera sabido que la imagen es la percepción de los grupos externos con base a su experiencia (con la empresa) y a la opinión de los demás, y no es cómo ella quería ser vista, habría desarrollado experiencias constructivas con la población local; habría propiciado desde un inicio -antes de que estalle la crisisrelaciones de igual a igual con los grupos de la sociedad civil y las autoridades locales, como indicamos en el punto 2 de esta sección.

Al sostener esto, no nos referimos a que la empresa debió aumentar sus actividades de apoyo social o filantrópicas -que sí eran conocidas por la población- sino a construir relaciones basadas en interacciones de igual a igual, como si ambas partes (población y empresa) fueran de verdad socias en los proyectos. Yanacocha debió mostrarse como una empresa dialogante, especialmente con los grupos más críticos, como una compañía que da la cara y que asume los compromisos tomados de la mano con sus socios’́. Ello habría sido fundamental para reconstruir su imagen corporativa golpeada ya por los pasivos de las cinco crisis previas.

6. El caso Conga muestra, finalmente, la relación directa que existe entre las relaciones de confianza empresa-población, la imagen corporativa y el acceso a la licencia social. Si las dos primeras son endebles o pobres, diríamos que es casi seguro que la población rechazará conceder la licencia social a una empresa, sobre todo a aquellas que operan en el llamado sector extractivo (mineras, petroleras, gasíferas) porque están en juego los recursos naturales que se encuentran dentro de los territorios locales.

Pareciera, entonces, que a Yanacocha le faltó también comprender el concepto de "licencia social" y los factores que condicionan su otorgamiento o rechazo. Le debe haber quedado como lección que uno de esos factores no es el poder económico de una empresa. 


\section{REFERENCIAS}

Alloza, A. (2019). Tendencias en Reputación y Gestión de Intangibles. Imagen y Comunicación, Revista Oficial del DIRCOM. 76, 11 - 21. Lima: LZC Perú.

Argenti, P. A. (2014). Comunicación Estratégica y su Contribución a la Reputación. Madrid: LID Editorial Empresarial.

Banco Central de Reserva del Perú. (2018). Memoria 2018. Lima: Banco Central de Reserva del Perú.

Bedoya, C., y Puma, L. (2016). Conflictividad Socioambiental en la Región de Cajamarca. Lima: Editatú Editores e Impresores de Victoria Adelaida Nureña Torres.

Defensoría del Pueblo. (2001). El caso del derrame de mercurio que afectó a las localidades de San Sebastián de Choropampa, Magadalena y San Juan, en la provincia de Cajamarca (Informe. $\mathrm{N}^{\circ} 62$ ). p. 6-51. Recuperado de: https://www.defensoria.gob.pe/wp-content/uploads/2018/05/informe_62.pdf.

Bozkurt, M. (2018). Corporate Image, Brand and Reputation Concepts and their Importance for Tourism Establishments. International Journal of Contemporary Tourism Research, 2, $60-66$

Calleja-Reina, M. A., Paniagua, F. J., y Victoria, J. S. (2018). Herramientas Digitales y Comunicación de Crisis: El papel de las Redes Sociales Según la Voz de los Expertos (2015). Estudios Sobre El Mensaje Periodistico, 24(2), 1147 - 1167. Recuperado de:http://dx.doi.org/10.5209/ESMP.62206

Capriotti, P. (2013). Planificación Estratégica de la Imagen Corporativa (4.ed). Malaga: IIRP- Instituto de Investigación en Relaciones Públicas.

Comisión Interamericana de Derechos Humanos. (6 de julio de 2012). IDH expresa su preocupación por agresiones ocurridas en el Departamento de Cajamarca, Perú. [Comunicado de prensa]. Recuperado de: http://www.oas.org/es/cidh/prensa/comunicados/2012/080.asp 
Comuneros quemaron maquinaria pesada de empresa minera. (17 de octubre de 2011). Panorama Cajamarquino, p. 3.

Corporate Excellence-Center for Reputation Leadership. (2020). La Hoja de Ruta de los Intangibles. Imagen y Comunicación, Revista Oficial del DIRCOM. 85, 23 - 27. Lima: LZC Perú.

Coombs, W. T. (1995). Choosing The Right Words: The Development of Guidelines for the Selection of the "Appropriate" Crisis- Response Strategies. Management Communication Quarterly : McQ (1986-1998), 8(4), 447. Recuperado de: http://www.proquest.com

Coombs, W. T. (2015). Ongoing Crisis Communication: Planning, Managing, and Responding (4.ed.). Estado Unidos: SAGE Publications, Inc.

Demuijnck, G., y Fasterling, B. (2016). The Social License to Operate. Journal of Business Ethics, 136(4), $675 \quad-\quad 685 . \quad$ Recuperado de: http://dx.doi.org/10.1007/s10551-015-2976-7

Freeman, R. E. (1983). Stockholders and Stakeholders: A New Perspective on Corporate Governance. California Management Review (Pre-1986), 25(3), 88 106. Recuperado de: http://www.proquest.com

Ejecutivo llevará Conga al TC y evalúa denuncia a autoridades. (28 de diciembre de 2011). La República. Recuperado de: https://larepublica.pe/politica/600679ejecutivo-llevara-conga-al-tc-y-evalua-denuncia-a-autoridades/

Escudero, G. (2010). Bien Común y Stakeholders. Navarra: Universidad de Navarra.

Freeman, R. E. (2010). Strategic Management: A stakeholder's approach. New York: Cambridge University Press.

Gainess-Ross, L. (2012). La Guerra por la Reputación. Harvard Business Review América Latina, 68 - 75.

Galecio, H. (2012). Conflictividad y manejo de crisis. Anda news: revista de la sociedad nacional de anunciantes, 16(122), 10- 14.

Gobierno regional ordenó intangibilidad de las cuencas en Cajamarca. (27 de diciembre de 2011). La República. Recuperado de: https://larepublica.pe/politica/600483gobierno-regional-ordeno-intangibilidad-de-las-cuencas-en-cajamarca/

Hunter, M. L., Van, L. N., y Besiou, M. (2017). Nuevas reglas para la gestión de crisis. Harvard Business Review América Latina, 6 - 16.

Instituto Nacional de Estadística e Informática. (2018). Censos Nacionales 2017: XII de Población, VII de Vivienda y III de Comunidades Indígenas. Recuperado de: https://www.inei.gob.pe/media/MenuRecursivo/publicaciones_digitales/Est/Li b1539/libro.pdf 
Instituto Nacional de Estadística e Informática. (2018). Evolución de la Pobreza Monetaria 2007-2018. Recuperado de: https://www.inei.gob.pe/media/MenuRecursivo/publicaciones_digitales/Est/Li b1646/libro.pdf

Instituto Nacional de Estadística e Informática. (2014). "Perú: Principales Indicadores Departamentales 2008-2014” [versión PDF]. Recuperado de: https://www.inei.gob.pe/media/MenuRecursivo/publicaciones_digitales/Est/Li b1205/index.html

Inversión de Conga irá a otros países si cambios no hacen rentable el proyecto. (27 abril de 2012). El Comercio. Recuperado de: https://archivo.elcomercio.pe/economia/peru/inversion-conga-ira-otros-paisessi-cambios-no-hacen-rentable-proyecto-noticia1407303?ref=flujo_tags_516716\&ft=nota_151\&e=titulo

Minera Yanacocha S.R.L. (19 de octubre de 2011). Resumen de marcha por la paz y el trabajo-entrevistas [archivo de video]. Recuperado de:https://www.youtube.com/watch?v=qofMej2eyYY

Minera Yanacocha S.R.L. (29 de mayo de 2012). Reporte de Sostenibilidad Yanacocha 2011. Recuperado de: http://www.yanacocha.com/wpcontent/uploads/REPORTE.pdf

Minera Yanacocha S.R.L. (2011). Proyecto Conga. Recuperado de: http://www.yanacocha.com/wp-content/uploads/CONGA.pdf

Minera Yanacocha S.R.L. (2019). Modificación del Estudio de Impacto de Yanacocha [folleto]. Perú: Autor.

Newmont sobre Conga: "Vamos a gastar el último sudor que tengamos para sacar el proyecto". (14 de marzo de 2012). El Comercio. Recuperado de: https://archivo.elcomercio.pe/economia/peru/newmont-sobre-conga-vamosgastar-ultimo-sudor-que-tengamos-sacar-proyecto-noticia1387251?ref=flujo_tags_516716\&ft=nota_160\&e=titulo

Newmont está dispuesta a corregir errores, afirmó su vicepresidente. (23 de julio de 2012). El Comercio. Recuperado de: http://archivo.elcomercio.pe/amp/economia/peru/newmont-esta-dispuestacorregir-errores-afirmo-su-vicepresidente-noticia-1432173

Newmont: en estos momentos no existen condiciones para proceder Conga. (21 de agosto de 2012). El Comercio. Recuperado de: https://archivo.elcomercio.pe/economia/peru/newmont-estos-momentos-noexisten-condiciones-proceder-conga-noticia-1458910

Remy, P. (2015). Manejo de crisis. ¿Qué hacer el día en que todo está en contra nuestra? Lima: Universidad Peruana de Ciencias Aplicadas (UPC). 
Roque Benavides sobre Conga: El problema es entre el Ejecutivo y el gobierno regional. (24 de junio de 2012). El Comercio. Recuperado de: https://archivo.elcomercio.pe/politica/gobierno/roque-benavides-sobre-congaproblema-entre-ejecutivo-gobierno-regional-noticia1432637?ref=flujo_tags_516716\&ft=nota_124\&e=titulo

Sheen, R. (2012). La estrategia del silencio ¿diluye o agrava una crisis? Imagen y Comunicación, Revista Oficial del DIRCOM, 31, 5-11. Lima: LZC Perú.

Sheen, R. (2016). La Cultura Organizacional y su Impacto en la Gestión Empresarial Un acercamiento a tres compañías peruanas. Lima: Fondo Editorial de la Universidad de Lima.

Sociedad Peruana de Derecho Ambiental. (24 de febrero de 2012). Vea el documental de Yanacocha sobre los beneficios que traería el proyecto Conga en Cajamarca. $L a$ Mula. Recuperado de: https://spdaactualidadambiental.lamula.pe/2012/02/24/vea-el-documental-deyanacocha-sobre-los-beneficios-que-traeria-el-proyecto-conga-encajamarca/spdaactualidadambiental/

Zazo, A. (19 de julio de 2017). La producción de oro en Perú, en profunda caída libre. OROINFORMACION. Recuperado de https://oroinformacion.com/laproduccion-de-oro-en-peru-en-profunda-caida-libre/ 